\title{
A Method for Promoting Interaction Awareness by Biological Rhythm in Elementary School Children
}

\author{
Kyoko Ito ${ }^{1,2}$, Kosuke Ohmori ${ }^{2}$, and Shogo Nishida ${ }^{2}$ \\ 1 Center for the Study of Communication-design, Osaka University \\ ito@sys.es.osaka-u.ac.jp \\ 2 Graduate School of Enginering Science, Osaka University, Osaka, 5608531, Japan
}

\begin{abstract}
Recently, in Japan, education about the ability to make decisions as part of a group composed of children with different ways of thinking has become more important. Therefore, discussion activities have been adopted in elementary school education. This study considers a method that supports discussion activities by making children aware of the "state" (i.e., atmosphere, progress) of their group during discussion, and of the ways they are influencing this state themselves. We developed a system which allows us to visualize the entrainment of the biological rhythm to present the group's state. An experiment using this system was conducted to clarify whether the children were aware of the group state during discussion, and how they were affected by this awareness. We found that this system has the potential to support children when considering ways of participating in the discussion. Also, it was found that the system can act as an interface, encouraging children to think about the importance of their listening to others in the group.
\end{abstract}

Keywords: Education support, Elementary school education, discussion activity, interaction, biological rhythm.

\section{Introduction}

Recently in Japan, education about the ability to make decisions in groups composed of children with different ways of thinking has become more important 1 . This is difficult to achieve with the traditional teaching style, where the teacher teaches while the students listen[2, therefore, discussion activities have been adopted[3]. In such an activity, a group composed of $5 \sim 6$ children discusses a complex theme, such as an energy/environmental issue. Taking into consideration the critical period, it has been found appropriate to adopt this activity as a part of elementary school education. The critical period is a theory about the specific period during the development of a child when he/she can construct a neural circuit efficiently and utilize it effectively in the long term [4].

In this type of activity, children learn how to make a decision in a group through communicating with each other. To heighten the learning effect of this activity, children need to realize the meaning of this activity by themselves $[5]$.

M. Kurosu (Ed.): Human-Computer Interaction, Part V, HCII 2013, LNCS 8008, pp. 421-430, 2013. (C) Springer-Verlag Berlin Heidelberg 2013 
Therefore, it is important for them to think about ways to participate in the discussion. The purpose of this kind of activity is to educate children about how to make group decisions, therefore they need to be aware of the "state" (i.e., atmosphere, progress) of the group during discussion when they decide how to participate in the discussion. In other words, each child should be aware of how he/she relates to the group's state. However, the state of a group changes continually during discussion, and since these changes are invisible, it is difficult for the children to be aware of them. Therefore, it is necessary to support discussion activities by making children "see" the group's state, and make them aware of the role they play in it.

The purpose of this study is to investigate a method that supports discussion activities by making children aware of the group's state and of the ways they themselves influence it. We will also clarify how the method affects the children's attitude during the discussion.

\section{Related Study}

In this section, we shall introduce several related studies about children's discussion activities, and several studies about various methods for supporting children's discussion using information technology.

Isomura investigates the meaning of the one-to-many communication between children and teacher in the lower grades of elementary school[5], showing how teachers educate children's abilities to speak up, and how this affects children. Matsuo looks into how experienced teachers initiate discussion activities [6]. Also, this study shows methods used by teachers to make and implement discussion rules. Sakai shows that giving a role to each child in the discussion is an effective strategy to make the activity proceed smoothly [7].

Other studies use electronic whiteboards or tabletop interfaces for supporting the discussion activity. Otsuki suggests encouraging children's participation in the discussion by using an interactive electronic whiteboard [8]. The purpose of using the whiteboard is to elicit group competition, which stimulates the desire of the children to take part in the activity. Kitahara suggests supporting discussion activities by using a tabletop interface 9 . This study uses the interface to make children's exchange of information proceed smoothly.

As mentioned in section I., children should think about ways to participate in the discussion activity by themselves. Creating rules and routines, as well as using tabletop interfaces can make discussion smooth, while using an electronic whiteboard may improve children's participation. Nevertheless, these methods do not make children aware of the group's state during discussion. This is where our study will bring something new and different from the above-mentioned approaches. 


\section{Awareness of Group Condition}

In order to support children's discussions, this study proposes a method to make children understand clearly the way the atmosphere in the group changes, and the role they themselves play in their group's general state. To achieve this, we take into consideration visualizing the information concerning the group's state. This section first describes what makes up the "state of the group", and then suggests a method to visualize it.

\subsection{Group's State during Discussion}

The ways children participate in a discussion can vary. For example, some children are good at speaking, some are good at listening, and some are good at thinking. Therefore, a child's discussion ability is one factor which decides his/her participation in the discussion. Children should learn how to use their abilities; They should also know that the best way is not the same for all, or in all situations. They should be taught to adopt one communication strategy or another based on how their ability affects the group's state. When teaching children how to make a group decision, each child should be taught to think about the best way to participate in the discussion by paying attention to the relation between his participation and the group.

So, what makes up the group's state? One component is the way children interact with each other in the discussion. Children should be aware that their interaction is an important factor in shaping the general atmosphere of the group discussion.

Usually, one participates in a discussion by speaking, listening, and thinking. Therefore, the interaction between children in discussion has the following components:

- Interaction through speaking - listening;

- Emotional interaction.

Information changes continually in discussion, and these changes are invisible. Therefore, this study tries to visualize the information. A method for extracting the interaction between children will be considered in 3.2

\subsection{A Method for Extracting Information about Children's Interaction}

The interaction between children in discussion has the following components:

- Interaction through speaking - listening;

- Emotional interaction.

The emotional interaction between children includes not only external information, but also internal information. Therefore, it is not enough to visualize 
the statements, the volume of the voice, facial expressions or nutation to show interaction. This study takes into consideration biomarkers, which show one's internal status 10. Some biomarkers, such as breath or heart rate, can be used to measure the biological rhythm. It is said that biological rhythm reflects one's internal status, and each person has their own rhythm. Watanabe shows that entrainment of biological rhythms occurs between two persons when they are communicating or having the same feelings. This is why in this study we will use information pertaining to the biological rhythm entrainment.

\subsection{Preliminary Research toward Using Biological Rhythm Entrainment}

We conducted a preliminary research to find a method of processing the biological rhythm entrainment to show the interaction between children.

The participants were 15 graduate students, divided into 5 groups of 3 . A 45 minute discussion session was held in each group, and the heart rate of each participant was measured during the discussion. After the discussion, each participant was asked to give details about how the discussion was going when their heart rate entrainment shows special features. Heart rate entrainment was calculated based on equation (1), as a correlation coefficient. Based on the 9 sets of data obtained in an interval of 3 minutes from every participant in the experiment, we calculated the following correlation coefficient.

$$
\begin{gathered}
C_{x y}=\frac{\sum_{i=1}^{n}\left(x_{i}-\bar{x}\right)\left(y_{i}-\bar{y}\right)}{\sqrt{\sum_{i=1}^{n}\left(x_{i}-\bar{x}\right)^{2}} \sqrt{\sum_{i=1}^{n}\left(y_{i}-\bar{y}\right)^{2}}} \\
x_{i}, y_{i}: \text { heart rate, } \bar{x}, \bar{y}: \text { average of } x_{i}, y_{i}, n: \text { number of data }
\end{gathered}
$$

The participants mentioned the following instances of an increase in the number of heart rate entrainment sets:

- Listening to the speaker;

- Forming group opinion.

These results show that visualizing the number of sets of biological rhythm entrainments can make participants aware of the group's state in the discussion, as mentioned in 3.1. Based on these results, we decided to use the correlation coefficient (formula (1)) to calculate the heart rate entrainment. From the analysis of the correlation coefficient data of each pair of participants, the threshold to determine whether the heart rate is entraining or not was set at 0.3 . 


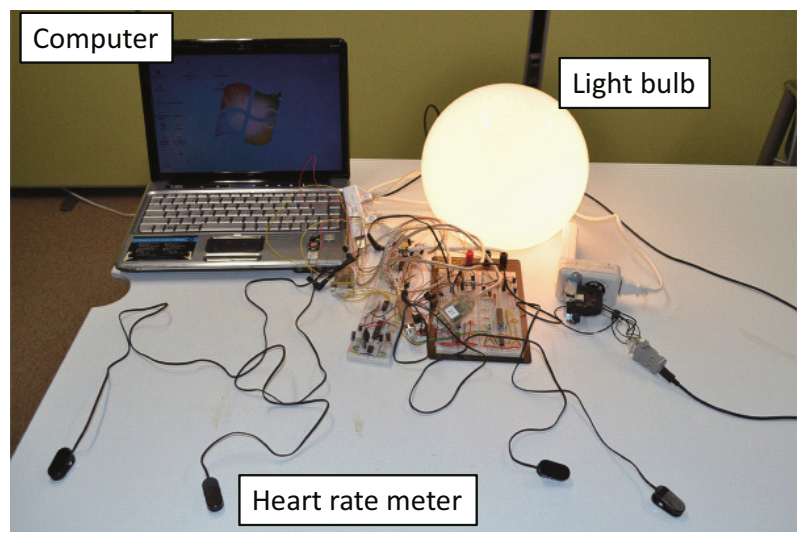

Fig. 1. Overview of the system*

*The greater the entrainment of children's heart rates, the brighter the light bulb

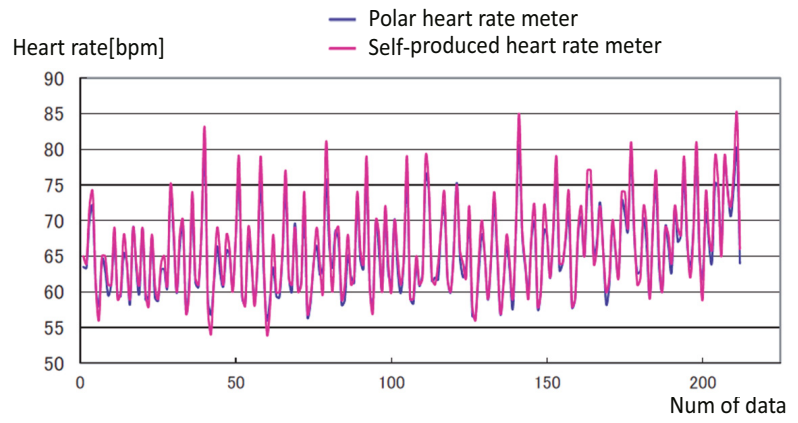

Fig. 2. Comparison between RS800CX and our heart rate meter

\subsection{Visualizing the Entrainment of the Biological Rhythm}

To visualize the entrainment of the biological rhythm, we developed the system shown in fig [1. Each participant's heart rate can be measured by placing a heart rate meter on their ear, which is noninvasive. The number of entrainment sets is calculated by a computer and made visible by changing the intensity of a light bulb.

We built the heart rate meter ourselves, and also conducted accuracy measurements comparing it with the heart rate meter made by Polar Electro (RS800CX). The result of the comparison for 3 minutes is shown in fig. The error was \pm $10 \%$.

The purpose of this study is to propose a method that supports discussion activities by making children aware of the group's state and of the role they play in shaping it, and to clarify how the method affects the children's attitude during the discussion. An experiment using this system was conducted. 


\section{Experiment}

\subsection{Purpose}

The purpose of this experiment is to clarify the following issues, while using our system in the discussion:

(A) How the children were aware of the group's state in discussion;

(B) How the children were affected by their awareness.

\subsection{Method}

\section{- Participants}

Thirty-three children (15 from 5th grade, 18 from 6 th grade) and 2 teachers participate in the experiment. The children are divided into 3 groups for each grade.

\section{- Experiment Flow}

The teachers decide the topics for discussion.

(i) Explanation (10 minutes): Children hear an explanation on the experiment, the topic of discussion, and the system.

(ii) Discussion (15 minutes): Every child wears a heart rate meter on the ear. Each group uses the system in the discussion. After 15 minutes, each group has to make a decision.

(iii) Interview with children (10 minutes): After the discussion, to investigate how children were aware of the group's state, each group is interviewed. The interviewer asks the following questions:

- How was the discussion going when the bulb was bright?

- How was the discussion going when the bulb was dark?

(iv) Presentation of the group decision (10 minutes): Each group presents their decision, then the teacher draws the conclusions.

(v) Interview with the teacher (10 minutes): After the discussion, each teacher is interviewed about whether the children were different from usual. The interviewer asks the following questions:

- What did the children think about the presentation of the system?

- How were the children reacting to the presentation of the system?

- How were the children different from everyday discussion?

\section{- Method of Analysis}

The interview data from the teacher is analyzed by a qualitative method called "modified grounded theory approach(M-GTA). This is a modified version of the "grounded theory approach"(GTA) [15. M-GTA is a method for reconstructing the process of real scientific hypothesis testing from the results. First, the data that can explain a concept is chosen from interview data, and some concepts are extracted from it. The concepts that are extracted are divided into categories based on the relations between them[11] 12] 13]. This method has come to be used in recent research about interface fields [14. 


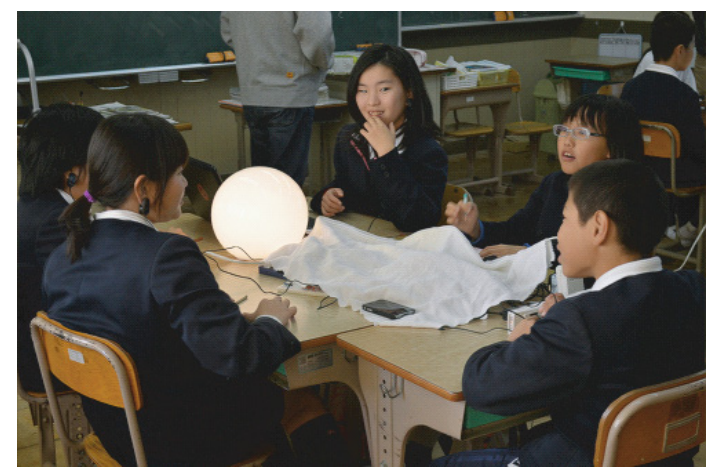

Fig. 3. Group in 5th grade using the system

Table 1. Results of interview with the children

\begin{tabular}{l|c|c}
\hline \multicolumn{1}{c|}{ Questions } & Results & Groups \\
\hline \multirow{2}{*}{$\begin{array}{l}\text { How was the discussion } \\
\text { going when the bulb } \\
\text { was bright? }\end{array}$} & Everyone was laughing & 3 \\
\cline { 2 - 3 } & Everyone was sighing at the same time & 2 \\
\cline { 2 - 3 } & It was bright even when l was not speaking & 1 \\
\cline { 2 - 3 } & Everyone was thinking something & 3 \\
\cline { 2 - 3 } & Everyone was thinking the same thing & 3 \\
\cline { 2 - 3 } & Everyone was paying attention to one person & 1 \\
\hline \multirow{2}{*}{$\begin{array}{l}\text { How was the discussion when the bulb } \\
\text { gas dark? }\end{array}$} & No one was speaking & 3 \\
\cline { 2 - 3 } & No one was listening to what was being said & 4 \\
\cline { 2 - 3 } & Talking about unrelated things & 2 \\
\cline { 2 - 3 } & Thinking different things from & 3 \\
& what was being said & \\
\hline
\end{tabular}

\subsection{Results}

The themes of discussion in each class were the following:

- 5th grade: How to reduce waste;

- 6th grade: How to save electricity.

Fig 3 shows a group in 5 th grade using the system in discussion.

Children's Awareness of the Group's State. Table 1 shows the results of the interview with the children. In this table, the question, result and number of the group that had the same answer are shown in this order.

From these results, it seems that the children were aware of how they were interacting with the others by listening or speaking. Also, it seems that they were aware of how their thoughts or feelings were relating with each other's. In addition, the appearance of keywords such as 'everyone' or 'at the same time' in the results of the interview shows that children were aware of how they were relating to the group's state. 


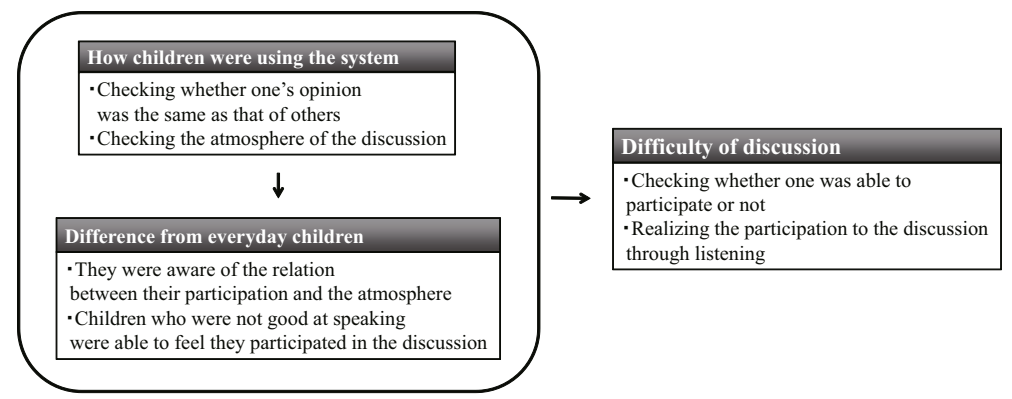

Fig. 4. Conceptual diagram obtained from the M-GTA analysis

Analysis of M-GTA. The length of the interview with the teacher was 10 minutes, and the data from the interview contained about 500 words. The results of the interview are below.

- Children were aware of the existence of a general atmosphere of the discussion, which is difficult to observe usually without using the system.

- Children were aware of the relation between their participation and the atmosphere of the discussion.

- Usually, children feel that they are not participating to the discussion if they do not speak and only listen, but using the system, they felt that they were participating to the discussion by listening, too.

- Children were checking whether their opinion was the same as that of the others.

Fig 4 shows the conceptual diagram which is the result of the analysis by MGTA.

From the analysis and the result of the conceptual diagram, we obtained the following explanation of the discussion using the system. In a usual discussion, it is difficult to check whether one is able to participate in the discussion or not. Also, it is difficult to be aware of one's the participation to discussion through listening. On the other hand, using the proposed system to check the difference or concurrence of opinion, or to check the atmosphere of discussion, children were able to overcome these difficulties. They noticed the relation between their participation and the atmosphere of the discussion. In addition, being aware of the relation between the general discussion atmosphere and their listening, children who were not good at speaking were able to feel that they were participating in the discussion, too.

These results are pointing to two main effects of making children aware of the group's state.

1. Children were aware of the relation between the atmosphere of discussion and their participation.

2. Children realized that listening is a way to participate in discussion. 


\subsection{Consideration}

The purpose of the system was to make children aware of the group's state in discussion and of how they relate to it. Through the experiment, we shed light on several ways that the children were affected by being aware of the group's state. Two main effects were brought to our attention:

The first effect was that the children were aware of the relation between the atmosphere of discussion and their participation. In this study, we explained that in order to consider what is the best way to participate in a discussion one needs to be aware of the relation between one's way of participating and the state of the group during discussion. Therefore, making children aware of the group's state in discussion can help them when they are trying to find and choose a way to participate in discussion.

Another effect was that children realized that listening is a way to participate in discussion. Speaking is an easy way to participate in a discussion because one can affect others or the group with their utterances. On the other hand, one does not affect others or the group directly by listening, so it is difficult to become aware of one's participation in discussion. Nevertheless, a number of studies about listening [16] 17] show that it is just as important as speaking. According to previous research, one's listening attitude affects the speaking attitude of the others 16. In addition, it has also been proven that a good listening attitude affects one's learning [17. Being aware of the group's state in discussion, and being aware of how one's way of participating affects the group's state will give children an opportunity to think about the effects listening has on the discussion.

\section{Conclusion}

Our work has considered a method that supports discussion activities by making children aware of the group's state (i.e., atmosphere or progress) during discussion, and also of the way they are influencing this state themselves. In order to present the group's state, we developed a system which allows us to visualize the entrainment of the biological rhythms. An experiment using this system was conducted to clarify whether the children were aware of the group during discussion, and how they were affected by this awareness.

Our findings suggest that it is indeed possible for this system to support children in considering ways of participating to the discussion by themselves. Also, it was found that the system can act as an interface which encourages children to think about the importance of their listening to others in the group.

Our future work includes conducting additional investigations in order to theorize system-assisted discussion methods. We also intend to clarify the effects of the system as an interface which helps children to think about the importance of their listening to others. 


\section{References}

1. Ministry of Education, Culture, Sports, Science and Technology: New Education Ministry guidelines (2011) (in Japanese)

2. Cazden, C.B.: Classroom discourse, 2nd edn. Heinemann, Portsmouth (2001)

3. Ichiyanagi, T.: How Do Students Listen to Others in Classroom Discussions?: Differences Across Classrooms and Subjects. Japanese Association of Educational Psychology 57, 361-372 (2009) (in Japanese)

4. Nagae, S.: Psychological study on early education and critical period of brain: school education and brain (1). In: Proceedings of Fukuoka University of Education, No.4, pp.95-101 (2009) (in Japanese)

5. Isomura, R., Machida, T., Muto, T.: A Turning Point of Classroom Communication in Lower Elementary School: Introducing "Everyone" to the Class. Japan Society of Development Psychology 16(1), 1-14 (2005) (in Japanese)

6. Matsuo, G., Maruno, S.: How Does an Expert Teacher Create Lessons So That Children Think Subjectively and Learn from Each Other? Students' Sharing of the Ground Rules for Classroom Discussion. Japanese Association of Educational Psychology 55, 93-105 (2007) (in Japanese)

7. Sakai, T.: Developing the method of educational guidance for discussion activity. The National Association of College Teachers for Japanese Language and Literature Education 119, 234-237 (2010) (in Japanese)

8. Otsuki, Y., Bandoh, H., Kato, N., Nakagawa, M.: An Educational Software Supporting Learning through Group Competition Using an Interactive Electronic Whiteboard and Its Effect. Information Processing Society of Japan 44(6), 16351644 (2003) (in Japanese)

9. Kitahara, K., Inoue, T., Shigeno, H., Okada, K.: A Tabletop Interface for Supporting Collaborative Learning. Information Processing Society of Japan 47(11), 3054-3062 (2006) (in Japanese)

10. Watanabe, T., Okubo, M., Kuroda, T.: Biological Signal Analysis of Entrainment in Face-to-Face Communication. The 52th National Convention of Information Processing Society of Japan, 419-420 (1996) (in Japanese)

11. Kinoshita, Y.: M-GTA Practice of Grounded Theory Approach, Kobundo (2005) (in Japanese)

12. Kinoshita, Y.: M-GTA Practice of Grounded Theory Approach in Field Study, Kobundo (2005) (in Japanese)

13. Kinoshita, Y.: All of M-GTAFMethod to practice Field Study, Kobundo (2007) (in Japanese)

14. Ando, M.: A Qualitative Approach for Psychological Factors in Use of Interactive Products. Journal of Human Interface Society 12(4), 345-356 (2010) (in Japanese)

15. Saiki, S.C.: Practice of Grounded Theory Approach Shinyosya (2008) (in Japanese)

16. Nagata, S., Kawakami, A.: The Influence of Cognitive Empathy on Small Group Learning. Journal of Japan Society for Educational Technology 32, 141-144 (2008) (in Japanese)

17. Igarashi, R., Maruno, S.: Development and Application of a Method for the Analysis of Classroom Discussion: Visualizing Mutual Links between Utterances in Transcripts. Journal of Japan Society for Educational Technology 32, 89-98 (2008) 